\title{
Legal Regulation of Environmental Problems of Coal Mining in Russian Federation
}

\author{
Marina Agienko ${ }^{1, *}$, Yuriy Volgin, ${ }^{1}$ Elena Moroz $^{1}$, and Tatyana Olofinskaya ${ }^{1}$ \\ ${ }^{1}$ Plekhanov Russian University of Economics, 650992, Kuznetskiy Prospect, 39. Kemerovo, Russia
}

\begin{abstract}
The legal side of subsoil use is one of the cornerstones of creating conditions for the transition to sustainable development. The will of the state - the guarantor of taking environmental measures should be implemented in the relevant legislative acts. The authors consider the main directions of legal regulation of the coal mining process in the territory of Russia. Basic legal documents regulating relations in the sphere of subsoil use of the Russian Federation are considered, problems of legislation on subsoil, water resources and land use are identified, and the main directions for its improvement are outlined. Also, a comparative analysis of the legal documents of the Russian Federation in this area is provided, that shows the obvious shortcomings of this issue from the point of view of the legislation.
\end{abstract}

\section{Introduction}

Today in the coal industry we can observe a significant production increase that is reflected in the environmental situation in the mining areas not in the best way. On the part of the state, these works are regulated by regulatory documents and acts. In this paper we will review and analyze how effective these regulations are and what issues remain uncontrolled by the state.

To date consideration at the state level, as well as the inclusion in the legislative framework of standards and requirements in the field of coal mining (processing) and use of coal, as well as requirements for the protection of the environment is of fundamental importance. The current state of the world economy shows that it is the coal industry that is among the top ten sectors that have the greatest impact on the country's economic potential, but at the same time the most destructive impact on the environment and the state of ecosystems. The potential for the development of the industry is limited by the availability of aging funds, technological imperfection of production, and also by the social tension associated with the impossibility of ensuring the proper quality and standard of living of the miners.

\section{Materials and Methods}

\footnotetext{
* Corresponding author: marinaivanovnaag@,mail.ru
} 
The main environmental problem with increasing coal production is the deterioration of human habitat. As a result of introducing humans into natural processes, landscape changes are negative in their consequences from erosion, pollution of the air basin and, as a result, depletion of biological diversity the problems associated with the need for reclamation of disturbed lands, the elimination of rock dumps and sludge pits, quenching mine dumps are typical for the industry.

As a result of all of the above, it follows that it is necessary to closely monitor and timely enforce the existing legal environmental requirements in the country for companies and enterprises engaged in mining activities [1]. The measures to be implemented should be directed primarily at the integrating and highly rational use of minerals, as well as associated natural components. Mining companies should ensure the full implementation of those standards and requirements that are established by law, as well as the requirements contained in the ecologically sound norms of related branches of the RF legislation on land use and use of water resources.

At the same time, coal mining requires the solution of a number of environmental problems that accompany it, among which we can distinguish the following:

- specifics of the chemical composition of the extracted coal;

- technological features of the methods and methods used for coal mining;

- ways of enrichment and use of deposits.

Next, we examine in more detail each of the above areas of problematic environmental issues.

\section{Results and Discussion}

The unfavorable factors in the extraction and use of coal are as follows:

- volumetric emissions of highly dispersed ash particles, as well as toxic microelements and their compounds of various origin that are usually formed as a result of heat treatment of coals;

- permanent discharges of highly mineralized sewage waters leading to a significant environmental problem and tangible damage to the environment, leading to a complete degradation of the quality of water from natural sources, and also leading to soil salinization (discharges of polluted sewage and transit waters in 2016 amounted to 812.3 MCUM);

- permanent negative, and more specifically, a destructive effect on the integrity of the earth's surface and subsoil;

adverse effects of various kinds and origin of toxic substances on the water and air environment, as well as solid soils, as a result of the most physico-chemical processes occurring in the dumps occurring in the dumps;

- the formation of solid waste in huge quantities, that accompanies the extraction, enrichment and use of coal;

- the destructive processes of exclusion of land that is purposely allocated for the storage of solid waste;

- permanent emissions of methane, toxic and greenhouse gases $\mathrm{NO} 2, \mathrm{SO} 2, \mathrm{CO} 2$ that accompany coal mining and combustion.

Speaking about the latter, according to Rosstat data, in 2016 the volume of emissions of pollutants into the atmosphere from all regions in Russia amounted to 31.6 million tons, of which 17.3 MT were emitted by stationary sources (non-mobile technological units, mainly industrial, as well as reservoirs, dumps, etc.). Any substance that enters the atmosphere in quantities exceeding the background values is considered pollutant and has an adverse effect on public health and the environment. 
The main requirements for the work on the extraction and processing of coal and oil shale are established by the RF Federal Law of June 20, 1996 "On state regulation in the field of coal mining and use, on the specifics of the social protection of workers in the coal industry organizations"[1].

According to this Federal Law, the specifics of the technological process of mining, as well as associated coal mining and processing operations, the continuous movement of workplaces and constantly changing working conditions, the complexity of mining and geological conditions of coal bedding, the negative impact of coal mining and processing operations on the Earth's surface, as well as on the environment, determine the need to specify and legislatively fix the principles of ensuring the safety of work in this industry.

As a result, the following principles became important aspects of coal mining:

- priority of human security and ecology;

- mandatory regulation of norms and rules for the safe conduct of this kind of work by the state;

- creation of safe and healthy working conditions in the workplace, as well as the accompanying in the provision of safe management of technological processes for the extraction and processing of coal and oil shale.

Despite the fact that the scope of regulation of the Federal Law of the Russian Federation No. 81-FZ includes coal mining, there are no referral standards to the subsoil legislation, as well as other environmental resources legislation. So, in the production of coal mining operations the requirements provided for not only by subsoil legislation, but also by water legislation (for example, when discharging drainage water into reservoirs) must be observed.

At the same time, it should be noted that there are important problems that have not been solved at the state level up to the present. For example, the Water Code of the Russian Federation still lacks any regulations or rules that would determine the procedure for collecting and discharging water into mine and mine water [2]. Since this type of water actually penetrates into the mines, coal opencasts and ore mines, it negatively affects the conditions of opening and exploitation of mineral deposits.

The process of mining at the stages of exploration and production of coal are subject to licensing and other powers of the Federal Agency for Subsoil Usage (Rosnedra), that performs the functions of rendering state services and managing state property in the sphere of subsoil use [3].

As it was legally approved and spelled out in regulatory legal acts and relevant documents, the process of coal mining and processing is technologically processed:

- only on the basis of an approved project, that, prior to approval, passed several types of state expertise, namely geological, economic, environmental and engineering;

- in accordance with mining and geological conditions.

The Federal Law No. 81-FZ limits itself just to reservations about the priority of environmental safety as part of the fundamental principles of ensuring the safety of work with coal.

As it is noted in the state approved subprogram "Ensuring the technological development of the industry and strengthening the scientific and technical base of companies and scientific centers", in the framework of the state program for the development of the Russian coal industry for the period up to 2030, the following focus areas in connection with non-traditional methods of coal mining are planned:

- improvement of existing technologies and introduction of more modern technological solutions in the process of underground coal gasification;

- improvement of technological processes for obtaining liquid fuel from coal, without changing the physical state of coal as a natural product. 
With regard to the solution of environmental problems that are directly related to all stages of work in the coal mining areas, it is proposed:

- thorough high-tech cleaning of mine water pumped from the field;

- improvement of existing and introduction of more modern methods of forecasting negative consequences on the environment as a result of the activities of enterprises and companies of the coal industry.

The next section of this state program presupposes work in the direction of ensuring environmental safety and maintaining a favorable ecological situation in the areas of industrial coal sites, which in itself is a rather difficult task. The works cover the following four main areas:

- revision and improvement of the existing regulatory and legal framework, as well as regulatory and methodological documentation that regulates the protection of the environment;

- regular implementation of organizational and technical measures, that will be under state control and will be directed straight at improving the efficiency of environmental activities;

- development and improvement of scientific and technical support;

- state control over the organization and implementation of technological and technical measures aimed at ensuring environmental safety of the environment in coal mining sites.

Also according to this program it is expected:

- introduction of special preferential terms of payments for negative impact on the environment, as well as preferential conditions for taxation of organizations specializing in environmental protection and environmental control;

- under the control of state bodies specializing in environmental control, switching to a system for normalizing emissions, as well as discharges of various kinds of origin that contain aggressive, highly polluting substances, and determining the best option for placing waste products on the basis of more modern technological solutions;

- partial or complete payment exemption for enterprises or companies engaged in coal mining for negative impact on the environmental condition of the environment at the time of development and implementation of innovative eco-technologies;

- revision and finalization of the existing industry normative and methodological documentation, that regulates the protection of the environment.

What organizational and technical actions of the state and controlling agencies should contribute to the effectiveness of environmental protection activities? The following areas of work are distinguished in the state program:

- survey of existing environmental protection facilities every 3 to 5 years to assess the possibilities for effective operation and technical condition;

- monitoring the timely improvement the professional skill (every 5 years) of employees of the nature protection facilities;

- conduct annual scientific and practical seminars on the basis of existing scientific centers for specialists and heads of environmental protection services, that are available at every major enterprise.

As part of the development of a set of scientific and technical solutions and technologies that will reduce or completely eliminate the negative consequences of the coal mining process, the following important areas of work stand out $[4,5]$ :

- highly effective cleaning of mine waters containing acids and alkalis that adversely affect the soil and the environment, purification of mineralized mine waters, cleaning of mine waters of complex chemical composition;

- control of existing facilities and possible increase in the efficiency of the more modern, modernized types of treatment facilities used in the coal mining industry;

- technologically safe and timely removal of toxic substances from the surfaces of objects and terrain, in order to reduce contamination to permissible standards in the coal mining 
area prior to their development and in the course of work with the subsequent use of methane;

- cleaning of gas mines from gaseous pollutants, as well as extraction of methane from the vent;

- minimization of release into the atmosphere of harmful substances and gases, with mass explosions in opencast coal mine;

- control and timely prevention of spontaneous combustion of rock dumps;

- use of more advanced technologies in the formation of fireproof overburden rock dumps;

- development and improvement of the microbiological method of reclamation of disturbed soils;

- use of processing technologies in the commodity products of the received waste in the process of coal mining and dirt extraction;

- inventory of abandoned dumps and disturbed soils, developing programs for their reclamation and further use.

In the section of the state program devoted to the descriptions of measures aimed at technological and technical solutions of environmental problems, the following important points of state regulation can be singled out:

- introduction high-tech, environmentally friendly, practically non-waste equipment or technologies into the industrial area of coal mining and processing;

- environmentalization technologies used in coal mining;

- intensive work to neutralize or significantly reduce emissions and discharges of pollutants;

- significant expansion of the use of innovative environmental technologies, as well as high-tech mining and processing equipment.

\section{Conclusion}

Thus, for today the state legal regulation of problems of the ecological safety arising in coal industry is not limited to the stated directions of work. In the future, a more detailed improvement of the legal mechanism in the coal industry is required, which should be based on a systemic approach. This option provides a functional interaction between the norms of the energy, environmental and other branches of legislation, as well as their balanced and highly effective correlation and interconnection.

\section{References}

1. The Federal law of Russian Federation No. 81-FZ of June 20 (Law Office, Moscow, 1996)

2. The Water Code of the Russian Federation No. 74-FZ of June 3 (Law Office, Moscow, 2006)

3. M. I. Agienko, E. P. Bondareva, G. V. Chistyakova, O. V. Zhironkina, O. I. Kalinina, IOP Conf. Ser.: Mater. Sci. Eng., 142, 012022 (2016)

4. Y. Scorgie, L. Burger, H. Annegarn, Socio-Economic Impact of Air Pollution Reduction Measures (NEDLAC, Rosebank, 2006)

5. Y. Scorgie, L. Burger, H. Annegarn, Study to Examine the Potential Socio-Economic Impact of measures to reduce air pollution from combustion, published by the Fund for Research into Industrial Development, Growth and Equity (NEDLAC, Rosebank, 2006) 